\title{
Susceptibility of rabbits venereally infected with Treponema paraluis-cuniculi to superinfections with Treponema pallidum
}

\author{
S GRAVES \\ From the Department of Microbiology, Monash University Medical School, Alfred Hospital, Prahran, \\ Victoria, Australia
}

SUMMARY Three female rabbits, venereally infected with Treponema paraluis-cuniculi between five and eight months previously, had treponeme-containing genital lesions and positive results to serological tests for syphilis. These rabbits and four normal female rabbits were challenged with Treponema pallidum intradermally on the shaved back with triplicate doses of $10^{4}, 10^{3}, 10^{2}$, and 10 treponemes (all at different sites). Significantly fewer syphilitic lesions developed in the rabbits previously infected with $T$ paraluis-cuniculi $(4 / 36)$ compared with the control rabbits $(37 / 48)$, and the mean size of the lesions (diameter of induration) was significantly less $(4 \mathrm{~mm}$ compared with $10 \mathrm{~mm})$. It appears that previous venereal infection of female rabbits with $T$ paraluis-cuniculi induced a level of cross-immunity against infection with $T$ pallidum. Protection was however not complete.

\section{Introduction}

Treponema paraluis-cuniculi and Treponema pallidum, which cause rabbit venereal spirochaetosis and human syphilis respectively, are closely related morphologically' and antigenically. ${ }^{2}$ Previous studies $^{2-4}$ have shown an appreciable level of immunity to $T$ pallidum in rabbits inoculated intratesticularly with $T$ paraluis-cuniculi between six and eight months previously.

In the experiment now reported venereally infected female rabbits (the natural route of infection with $T$ paraluis-cuniculi) were challenged with low serial 10 -fold doses of $T$ pallidum $\left(10^{4}, 10^{3}, 10^{2}\right.$, and 10$)$ intradermally on the shaved back, and the degree of syphilitic infection was measured by the percentage of inoculation sites at which lesions developed and their size. A comparison was made with normal female rabbits challenged with $T$ pallidum to ascertain the degree of protection against $T$ pallidum offered by the previous venereal infection with $T$ paraluis-cuniculi.

Address for reprints: Dr S Graves, Department of Microbiology, Monash University Medical School, Alfred Hospital, Prahran, Victoria 3181, Australia

Received for publication 12 March 1980

\section{Materials and methods}

INFECTION WITH T PARALUIS-CUNICULI

A male rabbit (rabbit No 82673) was experimentally infected with $T$ paraluis-cuniculi and placed in a pen with four normal female rabbits, as described. ${ }^{5}$ The four female rabbits became venereally infected, as shown by the development of treponeme-containing lesions and seroconversion about five months after cohabitation with the infected male rabbit. ${ }^{5}$ Six months afterwards, when lesions were still present in three of the four female rabbits, they were challenged with $T$ pallidum.

\section{CHALLENGE WITH $T$ PALLIDUM (NICHOLS} STRAIN)

$T$ pallidum was obtained from the testes of a rabbit inoculated intratesticularly with $5 \times 10^{7} \mathrm{~T}$ pallidum about 10 days previously. Details of procedure and elution medium used were as published. ${ }^{6}$ The same anaerobic medium was used to dilute the $T$ pallidum to $10^{5} / \mathrm{ml}$ and thence in serial 10 -fold dilutions to $10^{2} / \mathrm{ml}$ (under anaerobic conditions).

The four control and four $T$ paraluis-cuniculiinfected rabbits had their backs shaved and marked into a $3 \times 4$ grid, each of the 12 squares being approximately $15 \mathrm{~mm}$ in length. Into each square $0.1 \mathrm{ml}$ of $T$ pallidum suspension was inoculated 
intradermally, so that each rabbit received triplicate inoculations of $10^{4}, 10^{3}, 10^{2}$, and $10 \mathrm{~T}$ pallidum.

The rabbits were examined twice a week for five weeks and the development of indurated syphilitic lesions on the backs was recorded. The rabbits' backs were kept shaved during this period.

\section{SEROLOGICAL MONITORING}

The rapid plasma reagin (RPR) test was carried out according to the manufacturer's instructions (Commonwealth Serum Laboratories, Melbourne, Australia). Results were recorded as strongly positive, weakly positive, or negative. The Treponema pallidum haemagglutination assay (TPHA) was performed using the kit produced by Fujizoki Pharmaceutical Company Ltd. The manufacturer's instructions were followed. Only tires greater than $1 / 80$ were considered positive and therefore indicative of past or current treponemal infection. Known positive and negative control sera were included in each test series. Previous studies have shown that results to these two tests become positive in venereal rabbit spirochaetosis. ${ }^{5}$

\section{Results}

One of the $T$ paraluis-cuniculi-infected rabbits was excluded from the experimental analysis because it had been badly attacked by the male rabbit and had numerous mating bites and infected claw injuries on its back, making detection of classical indurated $T$ pallidum lesions at the site of inoculation very difficult.

As shown in the table, the rabbits which had previously been infected venereally with $T$ paraluiscuniculi had developed some degree of protection against challenge with $T$ pallidum, as shown by the smaller number of lesions which developed at the inoculation sites and their smaller size, even though the protection was not complete.

After venereal infection of the three female rabbits with $T$ paraluis-cuniculi they developed positive results to the RPR test and TPHA. The uninfected control rabbits had negative results. After challenge with $T$ pallidum the test rabbits continued to have positive results and the results for the control rabbits became positive in both serological test.

\section{Discussion}

Turner and McLeod ${ }^{4}$ and Turner et $a l^{3}$ carried out studies on the susceptibility of rabbits experimentally infected intratesticularly with $T$ paraluis-cuniculi to challenge with $T$ pallidum (Nichols strain and strain CJ). They found considerable, but not complete, protection. As they comment, their experiments were a severe test of the immune system of the $T$ paraluiscuniculi-infected rabbits, as their intradermal challenge inocula were approximately $2 \times 10^{6} T$ pallidum. Nevertheless some protection was evident by the absence, or slow development, or smaller size of the lesions after challenge with $T$ pallidum. Their results were sufficiently impressive for them to write, "While no (syphilis) vaccine is in sight, the problem (human syphilis) is sufficiently important to warrant the exploration of all avenues of approach, including the potentialities of $T$ cuniculi as an immunising agent."

Subsequent work, reported by Turner and Hollander $^{2}$ involved inoculating rabbits intratesticularly with $T$ paraluis-cuniculi (strain A) and eight months thereafter challenging with a low dose (500 treponemes) of $T$ pallidum (Nichols) intradermally on the shaved back. As in the earlier experiments partial protection was obtained.

The purpose of the experiment reported in this paper was to determine whether or not rabbits naturally infected by the venereal route (as distinct from experimental intratesticular inoculation) with $T$ paraluis-cuniculi were resistant to low challenge doses of $T$ pallidum (Nichols) given intradermally. From the results it appears that significant protection did occur. Low challenges $\left(10\right.$ and $\left.10^{2}\right)$ of $T$ pallidum failed to cause any observable lesions in the

TABLE Development of syphilitic lesions in normal rabbits and in rabbits previously infected with Treponema paraluiscuniculi on intradermal (id) challenge with four different doses of Treponema pallidum (Nichols strain)

\begin{tabular}{|c|c|c|c|c|}
\hline \multirow[b]{2}{*}{$\begin{array}{l}T \text { pallidum challenge } \\
\text { doses (id) }\end{array}$} & \multicolumn{2}{|l|}{ Normal female rabbits* } & \multicolumn{2}{|c|}{$T$ paraluis-cuniculi-infected female rabbits $\dagger$} \\
\hline & $\begin{array}{l}\text { No of } \\
\text { lesions/sites inoculated }\end{array}$ & $\begin{array}{l}\text { Diameter of lesions }(\mathrm{mm}) \\
\text { (mean } \pm S D)\end{array}$ & $\begin{array}{l}\text { No of } \\
\text { lesions/sites inoculated }\end{array}$ & $\begin{array}{l}\text { Diameter of lesions }(\mathrm{mm}) \\
(\text { mean } \pm S D)\end{array}$ \\
\hline $\begin{array}{l}10^{4} \\
10^{3} \\
10^{2} \\
10 \\
\text { Total }\end{array}$ & $\begin{array}{r}10 / 12 \\
10 / 12 \\
11 / 12 \\
6 / 12 \\
37 / 48\end{array}$ & $\begin{array}{r}11 \cdot 0 \pm 6 \cdot 9 \\
11 \cdot 1 \pm 3 \cdot 5 \\
7 \cdot 8 \pm 5 \cdot 7 \\
8 \cdot 3 \pm 3 \cdot 6\end{array}$ & $\begin{array}{l}3 / 9 \\
1 / 9 \\
0 / 9 \\
0 / 9 \\
4 / 36\end{array}$ & $\begin{array}{l}4 \cdot 0 \pm 3 \cdot 6 \\
4 \cdot 0 \\
\mathrm{NL} \\
\mathrm{NL}\end{array}$ \\
\hline
\end{tabular}

*Four rabbits

tThree rabbits

$\mathrm{NL}=$ no lesion 
immunised rabbits and higher challenges $\left(10^{3}\right.$ and $10^{4}$ ) caused significantly fewer and significantly smaller lesions in the immunised rabbits (table).

It appears that $T$ paraluis-cuniculi does offer some protection to rabbits against low challenge doses of $T$ pallidum. Would it do the same for humans, and could it be a potential vaccine against syphilis? Further studies, in both rabbits and humans, are required to clarify this important question.

I wish to thank Mr Ian McLean for his excellent technical assistance and Mr John Edmonds for his valuable advice and assistance. The kind permission of the Director of the Keith Turnbull Research Institute (Mr B Woodfield) for use of the rabbit-pens is acknowledged.

This work was supported by grants from the National Health and Medical Research Council, the Utah Foundation, the Danks Trust, the estate of the late George Adams, the Ian Potter Foundation, and Monash University, from whom funds are gratefully acknowledged.

\section{References}

1. Hougen $\mathrm{KH}$, Birch-Andersen $\mathrm{A}$, Jensen $\mathrm{HS}$. Electron microscopy of Treponema cuniculi. Acta Pathol Microbiol Scand (B) 1973; 81:15-26.

2. Turner TB, Hollander DH. Biology of the treponematoses. World Health Organisation Monograph series No. 35, Geneva: WHO, 1957.

3. Turner TB, McLeod CP, Updyke EL. Cross-immunity in experimental syphilis, yaws and venereal spirochetosis of rabbits. Amer J Hyg 1947; 46:287-95.

4. Turner TB, McLeod CP. Cross-immunity in experimental syphilis, yaws and venereal spirochetosis of rabbits. Trans Assoc Am Physicians 1942;57:265-6.

5. Graves SR, Edmonds J, Shepherd RC. Lack of serological evidence for venereal spirochetosis in wild Victorian rabbits and the susceptibility of laboratory rabbits to Treponema paraluis-cuniculi. Br J Vener Dis 1980; 56:381-6.

6. Graves SR, Sandok PL, Jenkin HM, Johnson RC. Retention of motility and virulence of Treponema pallidum (Nichols strain) in vitro. Infect Immun 1975; 12 (5): 1116-20. 